\title{
Achievements and challenges of higher education in Arab countries
}

\author{
Clementina Acedo
}

(C) UNESCO IBE 2011

The recent events in the Arab countries show how important education, information, and ICT communication can be in mobilizing young people and whole societies in seeking societal openness and justice, and in pushing further for social, economic, and political development and change. The present wave of awakening in the Arab region, represented in the group of featured countries-Egypt, Morocco, Tunisia, Syria, Lebanon, and Jordan-makes this issue of Prospects even more relevant, since it addresses, in a comparative way, several key factors that influence the development of higher education in the region. As education helps people develop their capacity to guide their own destiny and life plans, both individually and collectively, we observe with great interest what the authors in this issue have to say.

As we know, investment in education is a necessary condition for social and economic development, but it is by no means sufficient. The Arab countries represent a case in point: the links have been weak between education and economic growth, income distribution, and poverty reduction, despite considerable progress in the past forty years (World Bank 2008). In addition to the high levels of commitment to investment in education that most countries in the region still express, other conditions are necessary, including quality education, better distribution of educational attainment, and functioning labor markets. Education can certainly be used to tackle inequalities, but it can also create more social stratification and segmentation, which usually translate into differentials in employment, occupation, income, residence, and social class. Thus, a process of democratizing the educational structure and governance, and the learning process itself, is essential. Education remains a major force for both democracy and development and a catalyst for social change.

The above conclusion holds across all levels of education, but especially in the case of tertiary education. This is because higher education is generally considered to be "a repository and defender of culture, an agent of change in this culture, an engine for national economic growth, and an instrument for the realization of collective aspirations" (Johnstone 1998, p. 2).

C. Acedo $(\triangle)$

UNESCO IBE, P.O. Box 199, 1211 Geneva 20, Switzerland

e-mail: c.acedo@ibe.unesco.org 
Against this backdrop, the Arab region faces several challenges. The first is inequitable access to higher education. The Arab states have made remarkable improvements in expanding access and reducing the gender gap at all levels of instruction; for example, indexes for secondary and higher education are not significantly different from those in Latin America and East Asia, and the gender gap at the primary level is virtually closed. Yet, from an equity perspective, the poor tend to be left out of higher education, lacking the resources to afford that level of instruction. Another challenge is the trade-off between increasing access and improving the quality of education attainment. A greater focus on maintaining and enhancing quality is vital in the drive for increased access, as well as that for higher completion and attainment rates. A third significant challenge is to have higher education produce a mix of educational outcomes that is compatible with the demands of the labor market and the national aspirations for social, political, and economic development.

Meeting these challenges is not easy. It requires action on many fronts, including a more efficient use of available resources and the mobilization of additional ones to deal with an expected increase in demand for higher education. In the Arab states, the cohorts of young people aged 0-14 and 15-24 are among the largest in the world, at $45 \%$ and $21 \%$ of the total populations respectively (World Bank 2008), and this "youth bulge" will significantly affect the demand for education over the next 30 years.

Recurring issues related to this demographic pressure, tighter government resources, and governance appear to be more pressing now than ever before. Likewise, new challenges are emerging, resulting partly from the same factors that have fuelled recent growth and partly from new national developments and global pressures to reform their educational systems. Given this complex context, financing higher education in the Arab region is becoming increasingly difficult.

Because these challenges have important implications for education, development, and democracy in the region and beyond, it is crucial that they receive the attention they deserve. Therefore, this special issue is both timely and extremely relevant.

The articles in this volume are based on a multi-country research project initiated in 2009 by the Economic Research Forum (ERF), on specific issues that challenge the financing of higher education in the Arab region. Six country cases were presented: Egypt, Morocco, Tunisia, Syria, Lebanon, and Jordan. Each case study assessed higher education finance, from the point of view of three key issues: adequacy (relative to certain benchmarks), efficiency (both internal and external), and equity (along gender lines, level of income, and location). They also considered the future financing challenges that will result from demographic shifts and the demand for better quality, documented and assessed reforms to date, and offered recommendations for a desirable course of action in the future. This common set of issues allowed a comparative analysis at a later stage. The papers, authored by distinguished economists in the region, were discussed at various workshops and international conferences and also underwent external review. The outcome of this ambitious research project is presented in this special issue.

The discussion of the Arab states is extended to a global level in the Trends section of this volume, which features an article by Bikas Sanyal and D. Bruce Johnstone, prominent scholars whose research focuses on issues related to higher education finance. They analyze recent international trends in financing higher education and the implications of those trends for access and equity, as well for the changing role of the state and the involvement of new stakeholders. As the state is increasingly unable to bear the rising costs of higher education, they notice a growing role for self-financing, and for both the non-profit and forprofit private sectors, in sharing the enrolment and the cost burden of higher education. 
They analyze various types of private-public partnerships and the role they can play in financing higher education, while also noting that any solutions, as clear as they would be in concept, are fraught with difficulties in practice.

The authors highlight policy responses that could be applied to any efforts to finance higher education, especially in low- and middle-income countries: maintain public tax support; achieve greater efficiency; diversify the public institutions by "simultaneously increasing the resources (and efficiency) of a select number of research universities that can be dedicated to the creation of knowledge and the preservation of free inquiry", increase private revenues by charging modest tuition and other fees in public universities, encourage a growing private higher educational sector, implement financial assistance, and improve public middle and secondary education as a way to improve access to and participation in higher education. They also argue for a combination of support and participation in these policy initiatives by international organizations such as UNESCO and OECD, international development banks, NGOs, and international scholars and policy analysts.

The issues raised in this volume clearly indicate the broad spectrum of education concerns vis-à-vis development, economic growth, income distribution, gender equality, poverty alleviation, and democracy. Therefore, this volume will surely stimulate and inform higher education researchers, policy makers, and practitioners in varied contexts.

\section{References}

Johnstone, D. B. (1998). The financing and management of higher education: A status report on worldwide reforms. Washington, DC: World Bank.

World Bank (2008). The road not traveled: Education reform in the MENA region. Washington, DC: World Bank. 